\title{
Economic burden of childhood diarrhea in Burundi
}

\author{
Fulgence Niyibitegeka ${ }^{1}$, Arthorn Riewpaiboon ${ }^{2 *}$, Sitaporn Youngkong ${ }^{2}$ and Montarat Thavorncharoensap ${ }^{2}$
}

\begin{abstract}
Background: In 2016, diarrhea killed around 7 children aged under 5 years per 1000 live births in Burundi. The objective of this study was to estimate the economic burden associated with diarrhea in Burundi and to examine factors affecting the cost to provide economic evidence useful for the policymaking about clinical management of diarrhea.

Methods: The study was designed as a prospective cost-of-illness study using an incidence-based approach from the societal perspective. The study included patients aged under 5 years with acute non-bloody diarrhea who visited Buyenzi health center and Prince Regent Charles hospital from November to December 2019. Data were collected through interviews with patients' caregivers and review of patients' medical and financial records. Multiple linear regression was performed to identify factors affecting cost, and a cost model was used to generate predictions of various clinical and care management costs. All costs were converted into international dollars for the year 2019.

Results: One hundred thirty-eight patients with an average age of 14.45 months were included in this study. Twenty-one percent of the total patients included were admitted. The average total cost per episode of diarrhea was Int\$109.01. Outpatient visit and hospitalization costs per episode of diarrhea were Int $\$ 59.87$ and Int\$292, respectively. The costs were significantly affected by the health facility type, patient type, health insurance scheme, complications with dehydration, and duration of the episode before consultation. Our model indicates that the prevention of one case of dehydration results in savings of Int\$16.81, accounting for approximately 11 times of the primary treatment cost of one case of diarrhea in the community-based management program for diarrhea in Burundi.

Conclusion: Diarrhea is associated with a substantial economic burden to society. Evidence from this study provides useful information to support health interventions aimed at prevention of diarrhea and dehydration related to diarrhea in Burundi. Appropriate and timely care provided to patients with diarrhea in their communities and primary health centers can significantly reduce the economic burden of diarrhea. Implementing a health policy to provide inexpensive treatment to prevent dehydration can save significant amount of health expenditure.
\end{abstract}

\section{Introduction}

Despite the remarkable achievements globally in the fight against diarrheal diseases in the last two decades, diarrhea remains as one of the major public health problems in the world [1,2]. In 2016, it was estimated that diarrhea was responsible for approximately 446,000 deaths globally among children aged under 5 years [2].

\footnotetext{
* Correspondence: arthorn.rie@mahidol.ac.th

2Division of Social and Administrative Pharmacy, Department of Pharmacy, Faculty of Pharmacy, Mahidol University, 447 Sri-Ayuthaya Road, Rajathevi, Bangkok, Thailand

Full list of author information is available at the end of the article
}

However, despite the prevalence of diarrhea in all regions of the world, it has been reported that more deaths attributed to diarrhea occur in developing countries, especially in sub-Saharan Africa and south Asia [3]. For instance, in sub-Saharan Africa, diarrhea killed 290,724 children aged under 5 years or more than $65 \%$ of total global deaths [2]. Diverse factors have been reported, such as limited access to appropriate health care often due to financial issues, undernutrition, geographic inaccessibility, shortage of reliable access to safe water, and sanitation [4]. In Burundi, after malaria and pneumonia, diarrhea is the third leading

(c) The Author(s). 2021 Open Access This article is licensed under a Creative Commons Attribution 4.0 International License, which permits use, sharing, adaptation, distribution and reproduction in any medium or format, as long as you give appropriate credit to the original author(s) and the source, provide a link to the Creative Commons licence, and indicate if changes were made. The images or other third party material in this article are included in the article's Creative Commons licence, unless indicated otherwise in a credit line to the material. If material is not included in the article's Creative Commons licence and your intended use is not permitted by statutory regulation or exceeds the permitted use, you will need to obtain permission directly from the copyright holder. To view a copy of this licence, visit http://creativecommons.org/licenses/by/4.0/. 
cause of mortality among children under 5 years [5]. In 2016, it was estimated that the mortality rate due to diarrhea was 7 per 1,000 live births in Burundi [3].

In general, although diarrhea continues to kill people, it can be successfully prevented and treated $[3,6]$. While the treatment of acute moderate diarrhea with oral rehydration salts has shown successful results, severe diarrhea often becomes complicated with dehydration and requires emergency care with intravenous fluids, or it can lead to death. However, in developing countries, it is not easy to get this type of emergency health care. Therefore, prevention and promptness of treatment are key strategies in the management of diarrhea to save the lives. World Health Organization (WHO) proposes the following prevention measures: use of rotavirus vaccine; access to safe drinking water; regular hand washing with soap; improved sanitation; exclusive breastfeeding for the first 6 months of life; good personal and food hygiene; and the promotion of health education on the transmission mode [6].

Burundi has made various efforts to improve public health; in 2006, with the purpose of improving access to health care, Burundi introduced a health care system to provide free services to all Burundian children aged under 5 years and to pregnant women seeking care at public health facilities [7]. However, the Burundian health system faces many challenges, such as a shortage of qualified health professionals, unequal distribution of existing staff between urban and rural areas, and a shortage of essential drugs [7]. In response to the WHO recommendation on the introduction of the rotavirus vaccine into all national immunization programs in 2009, Burundi introduced the rotavirus vaccine into the Expanded Program of Immunization (EPI) under Gavi support in December 2013 [8]. Furthermore, to ensure promptness of treatment, the Burundi government recently implemented a community-based management program for diarrhea in children aged under 5 years [9]. The program consists of treating all cases of moderate diarrhea occurring in children aged under 5 years with oral rehydration salts and zinc by community health workers in their communities [9]. However, the the program is still limited to some health districts.

Despite the introduction of rotavirus vaccine and other efforts made by the government of Burundi, the prevalence of diarrhea remains significantly high. This may be explained by the diversity of the viruses that causes diarrhea, seasonal variation, and climate change [10-12]. In 2016, according to the Burundi Demographic and Health Survey (DHS), 23\% of all children aged under 5 years experienced at least one episode of diarrhea during the 2 weeks preceding the survey [13]. This suggests the necessity to increase the coverage of existing interventions and to implement new health interventions. However, extension or implementation of new interventions incurs new costs [14]. In the context of a limited budget, there is a need for evidence to guide policymaking and planning. Additionally, it has been demonstrated that costing studies, by indicating the economic burden of disease, can be a useful tool to raise awareness of the magnitude of the problem to decision-makers as well as to conduct cost-effectiveness analysis of potential health interventions in the prevention and treatment of diarrhea [15].

In Burundi, although the clinical burden of diarrhea is well known, the economic burden of diarrhea remains unknown. Therefore, this is a study in Burundi to provide economic evidence on the economic burden of diarrhea and the costs of clinical services and the management of diarrhea. The study aimed, firstly, to estimate total direct medical and non-medical costs and indirect costs related to the health care of diarrheal patients from the societal perspective; and secondly, to identify factors affecting costs in order to estimate the cost of clinical status as economic evidence to improve clinical management.

\section{Methods \\ Study design and sites}

This study was designed as a prospective cost-of-illness study using an incidence-based approach to calculate the total cost of a diarrheal episode. A societal perspective with a micro-costing approach was used to estimate the costs of diarrhea.

The study was carried out for a period of 2 months (November to December 2019) at two study sites located in Bujumbura, the economic capital city of Burundi, which were purposively selected: Prince Regent Charles Hospital (HPRC), which is a 600-bed tertiary care hospital, and Centre de Medecine Communautaire de Buyenzi $(\mathrm{CMCB})$, which is a primary care health center.

\section{Study criteria \\ Inclusion criteria}

Inclusion criteria were children aged under 5 years who visited the study health facilities, presented with acute non-bloody diarrhea as the first complaint, and whose caregivers consented to participate in the study.

\section{Exclusion criteria}

Exclusion criteria were children and their caregivers who were not able to communicate with the investigator in Kirundi, French or English, and children who presented with other acute diseases (e.g. Malaria) or very severe chronic diseases (e.g. HIV and malnutrition) for which diarrhea was assumed to be a related symptom or complication. 


\section{Sample size estimation}

To estimate the sample size, we used the formula as follows: $\left(Z_{\alpha / 2} \sigma / \varepsilon \mu\right)^{2}$, where $Z_{\alpha / 2}$ is the critical value (1.96 for an $\alpha$ of 0.05), $\sigma$ is the population standard deviation, $\mu$ is the population mean, and $\varepsilon$ is the precision required [16]. Due to a lack of similar studies in Burundi, we referred to a study carried out in Libya [17], in which the mean cost was US\$678.99, and the standard deviation was US\$499.12. Therefore, for a precision of $15 \%$, we estimated a minimum sample size of 93 patients. However, we recruited all the patients who consulted the study health facilities and met the study criteria within the study period.

\section{Cost valuation}

Cost components included in this study were direct medical cost (i.e. medicines, investigation, and routine service costs), direct non-medical cost (i.e. transportation, meals, accommodation, extra diapers, and informal care costs), and indirect cost (i.e. productivity loss due to premature mortality).

For direct medical cost calculation, the quantities of resources used were multiplied by the unit cost of each medical service. Due to limitations in the calculation of actual unit cost of medical services, the unit cost of outpatient visit and bed-day was derived from WHO$\mathrm{CHOosing}$ Interventions that are Cost-Effective (WHOCHOICE) [18]. Unit costs for drugs and medical supplies were taken from the purchasing price of the study health facilities, while unit costs for laboratory tests were taken from private providers.

For direct non-medical cost calculation, costs were determined by the total expenses reported by the patient's caregivers, obtained through interview. Regarding informal care cost estimation, the human capital approach was used to value the caregiver time loss [19]. The cost was estimated by multiplying the total number of days lost due to diarrhea by the daily Burundi per capita gross national income (GNI) [20].

Indirect costs due to premature death or mortality costs were calculated using the human capital approach [19]; the costs were a summation of the discounted value of per capita GNI during the period of working age. Forecasted per capita GNI was estimated based on an average rate of historical annual growth. A discount rate of $3 \%$ per year was used to convert future per capita GNI to present value [15].

The total direct medical cost was computed as the sum of the total drugs and medical supplies cost, total investigation cost, and total routine services cost at outpatient clinic and inpatient ward. The total direct nonmedical cost was estimated by summing up the total cost of transportation, meals, accommodation, informal care, and other diarrhea-related expenses (e.g. extra diapers). The total cost per episode of diarrhea patient was computed as the sum of the total costs before, during, and after admission or visit. All costs collected in Burundian Francs (BIF) were converted to the international dollar (Int\$) for the year 2019 using the purchasing power parity (PPP). The PPP conversion factor from the World Bank website was not yet available for the year 2019 at the time of analysis, thus, a proxy rate for the year 2018 was used (Int $\$ 1=651.052$ BIF) [21]. Costs in the past were inflated using the Consumer Price Index (CPI) of Burundi [22].

\section{Data collection}

The investigator introduced the study to the caregiver (parent or guardian) when the child was admitted to or visited the outpatient department for diarrhea. Then, we requested for consent to include the child in the study; if agreed, the caregiver was asked to sign a consent form. The data collection form was developed from the "WHO guidelines for economic burden of diarrheal disease with focus on assessing the costs of the rotavirus diarrhea" [23]. Data were collected by interviewing the patient's caregivers and reviewing the patient's medical and financial records. The collected data included patient demographics and clinical features (i.e. visit or admission information and resources used), health carerelated expenses (i.e. treatment, food, transportation, accommodation, and extra diapers), and caregiver time loss.

\section{Data analysis}

The SPSS version 21 was used for statistical analysis. Descriptive statistics were used to summarize all variables. Differences between study health facilities were compared using bivariate statistics. A $p$-value $<0.05$ was used to indicate statistical significance. To explore the factors affecting the cost of diarrhea, we performed a multiple linear regression analysis using a stepwise method. Since the cost data were not normally distributed, a natural log transformation was used to meet the criteria of normal distribution. Model diagnostics were also applied to check quality of the cost functions [24]. Log cost was calculated by multiplying the unstandardized coefficient by the average value of each predictor. Estimation of the forecasted cost was done through retransformation of the log cost using anti-log (exponential) form and then adjusted by the smearing factor, which was calculated by averaging the exponential values of unstandardized residuals [24].

\section{Results}

\section{Characteristics of included patients}

A total of 138 patients were recruited for this study. Demographic and clinical characteristics of the patients are summarized in Table 1 . Most of the patients were 
Table 1 Demographic and clinical characteristics of the patients

\begin{tabular}{|c|c|c|c|c|}
\hline Characteristics & All $(n=138)$ & Health center $(n=44)$ & Hospital $(n=94)$ & $P$-value* \\
\hline \multicolumn{5}{|l|}{ Demographic } \\
\hline \multicolumn{5}{|l|}{ Sex; n (\%) } \\
\hline Male & $83(60.14)$ & $31(70.45)$ & $52(55.32)$ & \multirow[t]{2}{*}{$0.091^{* *}$} \\
\hline Female & $55(39.85)$ & $13(29.54)$ & $42(44.68)$ & \\
\hline \multicolumn{5}{|l|}{ Insurance during admission or visit; n (\%) } \\
\hline Free health care & $119(86.23)$ & $44(100)$ & $75(79.79)$ & \multirow[t]{3}{*}{$0.016^{* *}$} \\
\hline MFP & $10(7.25)$ & $0(0.0)$ & $10(10.64)$ & \\
\hline Private insurance and personal payment & $9(6.52)$ & $0(0.0)$ & $9(9.57)$ & \\
\hline \multicolumn{5}{|l|}{ Age (months), } \\
\hline Mean & 14.45 & 13.42 & 14.94 & \multirow[t]{2}{*}{$0.712^{* * *}$} \\
\hline (SD, median) & $(9.67,11.36)$ & $(7.48,12.58)$ & $(10.54,11.27)$ & \\
\hline \multicolumn{5}{|l|}{ Clinical } \\
\hline \multicolumn{5}{|l|}{ Patient type; n (\%) } \\
\hline Outpatient & 109 (78.99) & $44(100)$ & $65(69.15)$ & \multirow[t]{2}{*}{$<0.001^{* *}$} \\
\hline Inpatient & $29(21.01)$ & $0(0.0)$ & $29(30.85)$ & \\
\hline \multicolumn{5}{|l|}{ Complication with dehydration; n (\%) } \\
\hline Without dehydration & $78(56.52)$ & $44(100)$ & $34(36.17)$ & \multirow[t]{2}{*}{$<0.001^{* *}$} \\
\hline With dehydration & $60(43.48)$ & $0(0.0)$ & $60(63.83)$ & \\
\hline \multicolumn{5}{|l|}{ Discharge outcome; n (\%) } \\
\hline Alive & $137(99.28)$ & $44(100)$ & 93 (98.94) & \multirow[t]{2}{*}{$1.000^{* * * *}$} \\
\hline Dead & $1(0.72)$ & $0(0.0)$ & $1(1.06)$ & \\
\hline \multicolumn{5}{|l|}{ Duration group before visit or admission; n (\%) } \\
\hline$\leq 2$ days & $73(52.90)$ & 27(61.36) & $46(48.94)$ & \multirow[t]{2}{*}{$0.173^{* *}$} \\
\hline$>2$ days & $65(47.10)$ & $17(38.64)$ & $48(51.06)$ & \\
\hline \multicolumn{5}{|l|}{ Duration before visit or admission; day } \\
\hline Mean & 2.99 & 2.30 & 3.19 & \multirow[t]{2}{*}{$0.030^{* * *}$} \\
\hline (SD, Median) & $(2.76,2.00)$ & $(1.96,2.00)$ & $(3.02,3.00)$ & \\
\hline \multicolumn{5}{|l|}{ Episode duration; day } \\
\hline Mean & 7.02 & 6.07 & 7.47 & \multirow[t]{2}{*}{$0.004^{* * *}$} \\
\hline (SD, Median) & $(4.97), 6$ & $(5.27), 4.50$ & $(4.79), 6.00$ & \\
\hline
\end{tabular}

MFP "Mutuelle de la Fonction Publique", a health insurance scheme for civil servants, SD standard deviation

${ }^{*}$ To compare between health center (CMC Buyenzi) and hospital (Prince Regent Charles), a $p$-value $<0.05$ was used as statistical significance

** Chi-square

Mann-Whitney U test

*****isher's Exact test

male $(60.1 \%)$ and the average age for whole sample was 14.45 months. A majority of the patients $(86 \%)$ were covered by the Free Health Care system. Between the different study sites, i.e. health center and hospital, there was no statistically significant difference regarding demographic characteristics of the patients. However, clinical characteristics of the patients differed significantly between the two health facilities ( $p$-value $<0.05)$, except for the outcome on discharge and episode duration in terms of group. Twenty-eight patients (21.0\%) were admitted with an average length of stay of 8.9 days. Sixty patients $(43.48 \%)$ had complications of dehydration and all were treated at the hospital. Regarding the outcome on discharge, one patient died. The mean duration of symptoms before consultation at the health facilities was 2.99 days. The average duration of diarrheal episode was 7.02 days.

\section{Health care services and resources utilization}

Table 2 shows major health care services and resource utilization in the two study health facilities. Overall, antibiotics were prescribed for $61.59 \%$ of cases and were more likely to be prescribed at the health center $(97.73 \%)$ compared to the hospital $(44.67 \%)(p<0.001)$. 
Table 2 Major health care services and resource utilization

\begin{tabular}{|c|c|c|c|c|}
\hline Characteristics & $\begin{array}{l}\text { All } \\
(n=138)\end{array}$ & $\begin{array}{l}\text { Health center } \\
(n=44)\end{array}$ & $\begin{array}{l}\text { Hospital } \\
(n=94)\end{array}$ & $P$-value* \\
\hline Antibiotics; n (\%) & $85(61.59)$ & $43(97.73)$ & $42(44.68)$ & $<0.001^{* *}$ \\
\hline Co-trimoxazole suspension $40 \mathrm{mg} / 200 \mathrm{mg}$ per $5 \mathrm{ml}$ & $37(26.81)$ & $36(81.82)$ & $1(1.06)$ & $<0.001^{* *}$ \\
\hline Ampicillin injection $1 \mathrm{~g}$ & $27(19.57)$ & $0(0.0)$ & $27(28.72)$ & $<0.001^{* *}$ \\
\hline Gentamicin injection 1 vial 80 mg & 14(10.14) & $\mathrm{O}(0.0)$ & 14(14.89) & $0.005^{* *}$ \\
\hline Metronidazole syrup $125 \mathrm{mg} 100 \mathrm{ml}$ & 14(10.14) & $10(22.73)$ & $4(4.26)$ & $0.002^{* * * *}$ \\
\hline Amoxicillin syrup 125 mg/5 ml & $10(7.25)$ & $4(9.09)$ & $6(6.38)$ & $0.726^{* * * *}$ \\
\hline Cefotaxime injection $1 \mathrm{~g} \mathrm{IM} / \mathrm{IV}$ & $7(5.07)$ & $0(0.0)$ & $7(7.45)$ & $0.097^{* * * *}$ \\
\hline Metronidazole injection $.500 \mathrm{mg} / 100 \mathrm{ml}$ & $7(5.07)$ & $0(0.0)$ & $7(7.45)$ & $0.097^{* * * *}$ \\
\hline Laboratory tests (\%) & $93(67.39)$ & $30(68.18)$ & $63(67.21)$ & $0.892^{* *}$ \\
\hline Full blood count & $60(43.48)$ & $0(0.0)$ & $60(63.83)$ & $<0.001^{* *}$ \\
\hline C-reactive protein (CRP) & $56(40.58)$ & $0(0.0)$ & $56(59.57)$ & $<0.001^{* *}$ \\
\hline Thick blood smear & $56(40.58)$ & $5(11.36)$ & $51(54.26)$ & $<0.001^{* *}$ \\
\hline Stool microscopy & $33(23.91)$ & $24(54.55)$ & $9(9.57)$ & $<0.001^{* *}$ \\
\hline Malaria rapid test & 15(10.87) & 15(34.09) & $0(0.0)$ & $<0.001^{* *}$ \\
\hline Ringer lactate $500 \mathrm{ml}$ & $60(43.48)$ & $0(0.0)$ & $60(63.83)$ & $<0.001^{* *}$ \\
\hline Paracetamol syrup 120 mg/5 ml & 28(20.29) & $27(61.36)$ & $1(1.06)$ & $<0.001^{* *}$ \\
\hline ORS & $37(26.81)$ & $33(75.00)$ & $4(4.26)$ & $<0.001^{* *}$ \\
\hline Zinc sulfate $20 \mathrm{mg}$ tablet & $41(29.71)$ & $32(72.73)$ & $9(9.57)$ & $<0.001^{* *}$ \\
\hline $\begin{array}{l}\text { Length of stay (day) }{ }^{\text {a }} \text {; mean } \\
\text { (SD), median }\end{array}$ & $\begin{array}{l}8.90 \\
(3.6), 9.0\end{array}$ & $\mathrm{n} / \mathrm{a}$ & $\begin{array}{l}8.90 \\
(3.6), 9.0\end{array}$ & $\mathrm{n} / \mathrm{a}$ \\
\hline Treatment before visit or admission; $\mathrm{n}(\%)$ & $51(36.96)$ & $6(13.64)$ & $45(47.87)$ & $<0.001^{* *}$ \\
\hline Treatment after admission/visit; n (\%) & $7(5.07)$ & $0(0.0)$ & $7(7.45)$ & $0.097^{* * * *}$ \\
\hline $\begin{array}{l}\text { Caregiver's time loss (day); mean } \\
\text { (SD), median }\end{array}$ & $7.45(8.91), 4$ & $2.72(1.89), 2$ & $9.66(9.98), 5$ & $<0.001^{* * *}$ \\
\hline
\end{tabular}

n/a not applicable, SD standard deviation, ORS Oral rehydration salts

"To compare between health center (CMC Buyenzi) and hospital (Prince Regent Charles), a $p$-value $<0.05$ was used as statistical significance

** Chi-square

${ }^{* * *}$ Mann-Whitney U test

${ }^{* * * * *}$ Fisher's Exact test

${ }^{a}$ for inpatients

The most commonly used antibiotics were co-trimoxazole oral suspension $(26.81 \%)$ followed by ampicillin and gentamicin injections at a rate of 19.57 and $10.14 \%$, respectively. The prescription patterns between the health center and hospital were significantly different $(p<0.001)$. Laboratory tests were requested for $67.39 \%$ of total cases, and the most common test was full blood count (43.48\%) followed by C-reactive protein (40.58\%) and thick blood smear for malaria microscopy (40.58\%). Full blood count and C-reactive protein were exclusively requested at the hospital, while malaria rapid test was performed only at the health center. There were significant differences for all laboratory tests between the health center and hospital $(p<0.001)$. Intravenous fluids were given to $43.48 \%$ of patients, all at the hospital, while oral rehydration salts were given to $26.81 \%$ of patients. Most of the other medicines prescribed were different compounds of zinc (29.71\%) followed by paracetamol syrup (20.29\%).
Overall, 36.96\% of patients sought treatment or care before visit or admission to the study health facilities. However, when compared to the health center, patients who consulted at the hospital were more likely to have received care before $(p<0.001)$. Additional care from other health facilities after receiving treatment at the study health facilities was sought by only $5.07 \%$ of total patients. The average time loss of caregivers was 7.45 days. Caregiver time loss for the hospital patients was higher than that of the health center patients $(p<0.001)$.

The unit cost of commonly used drugs, medical consumables, laboratory tests, and services are presented in Table 3.

\section{Description of cost}

Table 4 summarizes different types of cost per diarrheal episode by health facility type. The average direct medical cost per diarrheal episode was Int\$77.24. Before visit 
Table 3 Unit cost of major service and resource utilization (value in 2019)

\begin{tabular}{|c|c|c|c|}
\hline \multirow[t]{2}{*}{ Item name } & \multirow[t]{2}{*}{ Unit } & \multicolumn{2}{|l|}{ Unit cost (Int\$) } \\
\hline & & Health center & Hospital \\
\hline \multicolumn{4}{|l|}{ Drugs } \\
\hline syrup 125 mg/5 ml & $100 \mathrm{ml}$ bottle & 1.53 & 2.02 \\
\hline Ampicillin injection $1 \mathrm{~g}$ & $1 \mathrm{~g}$-vial & $\mathrm{n} / \mathrm{a}$ & 0.82 \\
\hline Cefotaxime injection $1 \mathrm{~g}$ IM/IV & $1 \mathrm{~g}$-vial & $\mathrm{n} / \mathrm{a}$ & 1.30 \\
\hline Gentamicin injection 1 vial 80 mg & 80 mg-vial & $\mathrm{n} / \mathrm{a}$ & 0.34 \\
\hline Metronidazole syrup 125 mg $100 \mathrm{ml}$ & $100 \mathrm{ml}$ bottle & 1.44 & 1.37 \\
\hline Metronidazole injection 500 mg/100 ml & $100 \mathrm{ml}$ bottle & $\mathrm{n} / \mathrm{a}$ & 1.21 \\
\hline Paracetamol syrup $120 \mathrm{mg} / 5 \mathrm{ml}$ & $100 \mathrm{ml}$ bottle & 1.42 & 1.13 \\
\hline Co-Trimoxazole 40 mg/200 mg per $5 \mathrm{ml}$ & $50 \mathrm{ml}$ bottle & 1.45 & 1.45 \\
\hline Ringer lactate solution & $500 \mathrm{ml}$ & $\mathrm{n} / \mathrm{a}$ & 1.93 \\
\hline ORS & 1 packet & 0.40 & 0.40 \\
\hline Zinc sulfate $20 \mathrm{mg}$ & 1 tablet & 0.06 & 0.06 \\
\hline \multicolumn{4}{|l|}{ Medical supplies } \\
\hline Catheter court IV UU $24 \mathrm{~g}$ & 1 piece & $n / a$ & 0.44 \\
\hline Examination gloves & 1 pair & 0.65 & 0.65 \\
\hline Syringe a UU 5 ml & 1 piece & $\mathrm{n} / \mathrm{a}$ & 0.14 \\
\hline \multicolumn{4}{|l|}{ Laboratory tests } \\
\hline Stool microscopy & 1 test & 5.38 & 5.38 \\
\hline Thick blood smear & 1 test & 3.07 & 3.07 \\
\hline Full blood count & 1 test & 15.36 & 15.36 \\
\hline C-reactive protein (CRP) & 1 test & 15.36 & 15.36 \\
\hline Malaria Rapid test & 1 test & 7.68 & 7.68 \\
\hline Routine OPD service & 1 visit & 1.35 & 1.98 \\
\hline Routine IPD service & 1 bed day & $\mathrm{n} / \mathrm{a}$ & 4.44 \\
\hline Informal care & 1 day loss & 2.04 & 2.04 \\
\hline
\end{tabular}

n/a not available

or admission, $36.96 \%$ of patients sought medical care, and the average cost was Int\$5.73. During admission, the average medical cost was Int\$71.42. Drugs and medical supplies formed a majority of the cost during admission with an average amount of Int $\$ 39.92$, followed by investigation cost estimated to be Int $\$ 22.07$ and routine service cost of Int\$9.43. After visit or discharge, 5.07\% of all patients sought medical care with an average medical cost of Int $\$ 0.09$. Comparing the two health facilities, direct medical cost per each type and component was significantly higher for the hospital, except for the cost after visit or discharge.

The average direct non-medical cost was Int\$31.77 per diarrheal episode. Informal care was the largest component with a cost estimated to be Int $\$ 15.90$, followed by transportation and meal expenses with an average cost of Int\$9.36 and Int\$3.58, respectively. When comparing between health center and hospital, there was a statistically significant difference in terms of total direct medical cost, transportation, and meal-related expenses, as well as informal care cost for the whole diarrheal episode. No significant statistical difference was observed for other diarrhea-related expenses when comparing the two health facilities, and the overall average cost was Int\$2.93. There was no report on accommodation expenses related to the illness for all patients included in this study.

The cost per type of clinical service and health facility is presented in Table 5. The average cost per episode of outpatient visit and inpatient admission was Int $\$ 59.87$ and Int $\$ 292$, respectively. The cost of outpatient visit at the hospital and health center (Int\$84.07 versus Int\$24.67) was significantly different.

For one fatal case, the indirect cost that included productivity loss due to premature death was Int\$31,963.20. The total cost of illness, including direct costs incurred before death and indirect cost, was estimated to be Int $\$ 32,000.53$. 
Table 4 Cost per episode (Int\$ in 2019) by health facility type and cost components

\begin{tabular}{|c|c|c|c|c|c|c|c|c|c|c|}
\hline \multirow[t]{2}{*}{ Type of cost } & \multicolumn{3}{|c|}{ All $(n=137)$} & \multicolumn{3}{|c|}{ Health center $(n=44)$} & \multicolumn{3}{|c|}{ Hospital $(n=94)$} & \multirow[t]{2}{*}{$P$-value } \\
\hline & Mean & SD & Median & Mean & SD & Median & Mean & SD & Median & \\
\hline Direct medical cost & 77.24 & 94.92 & 41.64 & 15.35 & 8.80 & 15.06 & 106.52 & 102.88 & 71.67 & $<0.001$ \\
\hline Before visit/admission & 5.73 & 12.32 & 0.00 & 1.83 & 5.35 & 0.00 & 7.57 & 14.15 & 0.00 & $<0.001$ \\
\hline Visit/admission & 71.42 & 92.36 & 39.99 & 13.53 & 7.13 & 12.23 & 98.82 & 101.12 & 66.24 & $<0.001$ \\
\hline Drugs and medical supplies & 39.92 & 63.43 & 13.39 & 5.40 & 2.36 & 4.82 & 56.26 & 71.46 & 33.87 & $<0.001$ \\
\hline Investigation cost & 22.07 & 24.19 & 13.06 & 6.63 & 5.39 & 5.38 & 29.38 & 26.14 & 35.33 & $<0.001$ \\
\hline Routine services & 9.43 & 15.93 & 1.98 & 1.50 & 0.43 & 1.35 & 13.18 & 18.19 & 1.98 & $<0.001$ \\
\hline After visit/admission & 0.09 & 0.83 & 0.00 & 0.00 & 0.00 & 0.00 & 0.13 & 1.00 & 0.00 & 0.332 \\
\hline Direct non-medical cost & 31.77 & 36.82 & 18.57 & 9.32 & 6.64 & 8.59 & 42.39 & 40.36 & 30.06 & $<0.001$ \\
\hline Transportation $^{\mathrm{a}}$ & 9.36 & 14.51 & 4.61 & 1.60 & 2.22 & 1.08 & 13.03 & 16.33 & 7.53 & $<0.001$ \\
\hline Meal $^{a}$ & 3.58 & 6.79 & 0.92 & 0.80 & 2.41 & 0.00 & 4.90 & 7.74 & 2.30 & $<0.001$ \\
\hline Accommodation $^{a}$ & 0.00 & 0.00 & 0.00 & 0.00 & 0.00 & 0.00 & 0.00 & 0.00 & 0.00 & 1.000 \\
\hline Informal care ${ }^{a}$ & 15.90 & 19.17 & 8.59 & 5.83 & 4.05 & 4.29 & 20.66 & 21.54 & 10.74 & $<0.001$ \\
\hline Others $^{\mathrm{a}}$ & 2.93 & 9.42 & 0.00 & 1.09 & 4.08 & 0.00 & 3.80 & 11.00 & 0.00 & 0.205 \\
\hline Total cost per episode & 109.01 & 123.35 & 59.59 & 24.67 & 12.70 & 23.82 & 148.91 & 131.93 & 98.64 & $<0.001$ \\
\hline
\end{tabular}

SD standard deviation

*to compare between health center and the hospital with Mann-Whitney test, a $p$-value $<0.05$ was used as statistical significance

${ }^{a}$ include the cost before, during and after visit or admission

\section{Estimates of annual economic burden of diarrhea in Burundi}

As this study was conducted at a primary health center and a tertiary hospital, to estimate the cost of diarrhea in secondary care (i.e. district hospital), our estimated cost of diarrhea for a tertiary hospital was adjusted by the ratio of the unit cost at secondary hospital (Int\$2.01) and tertiary hospital (Int\$2.1) from WHO-CHOICE estimates [18]. Therefore, the cost of outpatient visit at district hospital was estimated to Int\$84.07 $\times 2.01 / 2.10=$ Int $\$ 80.47$. The admission cost at district hospital was estimated to Int $\$ 292 \times 2.01 / 2.1=$ Int $\$ 279.49$. According to the DHS [13], of the total patients with moderate diarrhea, the proportion of utilization of outpatient services was $92.87,5.02$, and $2.11 \%$ for health center, district hospital, and tertiary hospital, respectively. The nationwide cost of outpatient visit was therefore estimated to Int $\$ 24.67 \times 0.9287+\quad$ Int $\$ 80.47 \times 0.0502+\quad \operatorname{Int} \$ 84.07 \times$ $0.0211=$ Int $\$ 28.72$. The proportions of utilization of inpatient admissions were 70.39 , and $29.61 \%$ for district and tertiary hospital, respectively. Therefore, the average nationwide cost for inpatient cost was estimated to Int $\$ 279.49 \times 0.7039+$ Int $\$ 292 \times 0.2961=$ Int\$283.19. Regarding mild diarrhea, which does not require medical attention, medication cost was assumed to be zero, according to the DHS. However, a loss of income (Int\$2.14) due to absence from work was assumed at half of the average duration patients waited for a consultation at the study health facilities.

From the DHS [13], 41\% of diarrheal episodes were mild and, therefore, did not require consultation for medical care. The remaining 59\% required care from

Table 5 Distribution of cost per episode (Int\$ in 2019) by type of patients and health facility

\begin{tabular}{|c|c|c|c|c|c|c|c|c|c|c|c|c|c|}
\hline \multirow[t]{2}{*}{ Patient type } & \multicolumn{4}{|c|}{ All $(n=137)$} & \multicolumn{4}{|c|}{ Health center $(n=44)$} & \multicolumn{4}{|c|}{ Hospital $(n=93)$} & \multirow[t]{2}{*}{$p$-value* } \\
\hline & $n$ & Mean & SD & Median & $\mathrm{n}$ & Mean & SD & Median & $\mathrm{n}$ & Mean & SD & Median & \\
\hline \multicolumn{14}{|l|}{ Outpatient } \\
\hline DMC & 108 & 39.71 & 37.06 & 24.77 & 44 & 15.35 & 8.80 & 15.06 & 64 & 56.46 & 39.76 & 50.49 & $<0.001$ \\
\hline DnMC & 108 & 20.16 & 22.14 & 13.89 & 44 & 9.32 & 6.64 & 8.59 & 64 & 27.61 & 25.77 & 19.41 & $<0.001$ \\
\hline Total cost & 108 & 59.87 & 51.00 & 43.52 & 44 & 24.67 & 12.70 & 23.82 & 64 & 84.07 & 53.37 & 70.61 & $<0.001$ \\
\hline \multicolumn{14}{|l|}{ Inpatient } \\
\hline DMC & 29 & 217.01 & 113.34 & 182.94 & 00 & $\mathrm{n} / \mathrm{a}$ & $\mathrm{n} / \mathrm{a}$ & $\mathrm{n} / \mathrm{a}$ & 29 & 217.01 & 113.34 & 182.94 & $\mathrm{n} / \mathrm{a}$ \\
\hline DnMC & 29 & 74.99 & 47.51 & 59.54 & 00 & $\mathrm{n} / \mathrm{a}$ & $\mathrm{n} / \mathrm{a}$ & $\mathrm{n} / \mathrm{a}$ & 29 & 74.99 & 47.51 & 59.54 & $\mathrm{n} / \mathrm{a}$ \\
\hline Total cost & 29 & 292.00 & 141.29 & 239.02 & 00 & $\mathrm{n} / \mathrm{a}$ & $\mathrm{n} / \mathrm{a}$ & $\mathrm{n} / \mathrm{a}$ & 29 & 292.00 & 141.29 & 239.02 & $\mathrm{n} / \mathrm{a}$ \\
\hline
\end{tabular}

n/a not applicable (no inpatient care at health center), DMC Direct medical cost, DnMC Direct non-medical cost, SD standard deviation

*To compare between outpatient health center and outpatient hospital employing Mann-Whitney test, a $p$-value $<0.05$ was used as statistical significance 
health facilities. According to this study, of the total patients included, $21 \%$ were admitted and $79 \%$ were treated within the outpatient visit. Therefore, we estimated the proportions of diarrheal cases requiring hospitalization and those managed within the outpatient visit at $21 \times 59 / 100=12 \%$, and $79 \times 59 / 100=47 \%$, respectively.

According to the DHS [13], the incidence of diarrhea was 3.9 episodes per person-year. With a population of children under 5 years estimated to be 2,230,568 in 2019 [25], the total number of diarrheal episodes was estimated to be $8,681,336$ and composed of 3,559,348 mild cases managed at home; 4,046,371 outpatient visits; and 1,075, 618 admissions. The mortality rate from diarrheal diseases in Burundi was 7 per 1,000 live births according to a UNICEF report [3], resulting in 3,327 deaths in 2019. The annual economic burden of diarrhea was, therefore, estimated to Int $\$ 534,915,134 \quad(3,559,348$ mild cases $\mathrm{x}$ Int $\$ 2.14+4,046,371$ outpatient cases $x$ Int $\$ 28.24+1,075$, 618 admitted cases $\mathrm{x}$ Int $\$ 259.72+3327$ fatal cases $\mathrm{x}$ Int $\$ 32,000.53)$.

\section{Analysis of factors affecting cost}

As shown in Table 6, six variables significantly positively affected the total cost-of-illness: health facility type, patient type, duration of the episode before consultation, antibiotics use, health insurance scheme (MFP), and complications with dehydration. Adjusted $R^{2}$ was 0.773 . The variables excluded from the final model were age and private insurance.

For analysis of assumptions and model diagnostics [24], no funnel shape was observed for the scatter plot of residuals confronted to predicted values and all

Table 6 Multiple linear regression analysis of the cost

\begin{tabular}{|c|c|c|c|}
\hline Variables & $\beta$ & SE & $P$-Value \\
\hline Constant health facility type (ref: health center) & 8.991 & 0161 & $<0.001$ \\
\hline Hospital & 0.907 & 0.16 & $<0.001$ \\
\hline \multicolumn{4}{|l|}{ Patient type (ref: outpatient) } \\
\hline Inpatient & 1.28 & 0.17 & $<0.001$ \\
\hline \multicolumn{4}{|l|}{ Antibiotics use (ref: No use) } \\
\hline Use & 0.451 & 0.138 & $<0.001$ \\
\hline \multicolumn{4}{|l|}{ Episode before consultation (ref: episode $\leq 2$ days) } \\
\hline Episode $>2$ days & 0.285 & 0.092 & 0.002 \\
\hline \multicolumn{4}{|l|}{ Insurance scheme (ref: free health care scheme) } \\
\hline MFP & 0.589 & 0.182 & 0.002 \\
\hline \multicolumn{4}{|l|}{ Complication with diarrhea (ref: no dehydration) } \\
\hline Dehydration & 0.275 & 0.127 & 0.032 \\
\hline
\end{tabular}

Dependent variable $=$ Natural logarithm of total cost of illness of diarrhea Adjusted $R^{2}=0.773\left(R^{2}=0.778\right)$

MFP "Mutuelle de la Fonction Publique", a health insurance scheme for civil servants, Ref reference

A $p$-value $<0.05$ was used as statistical significance predictors, confirming homoscedasticity. The test of independence of residuals was shown by the DurbinWatson value of 2.034, which falls in the acceptable range (1.5-2.5). The condition index was 10.47, and therefore, the condition for no multicollinearity that requires the condition index to be less than 30 was met. The average Cook's distance was 0.008 and the range was $0.000-0.07$. Therefore, the condition of less than 1 , indicating no influential observation, was observed.

In clinical practice, oral rehydration salts (ORS) are recommended for diarrhea to prevent dehydration. To provide economic evidence of the significance of ORS, the costs of patients with dehydration and without dehydration were estimated. For other predictor variables, average values were assumed constant. As a result, the costs of patients with dehydration and without dehydration were Int $\$ 69.92$ and Int\$53.11, respectively. The resulting difference (Int\$16.81) was savings if dehydration was prevented. In the community-based management of diarrhea, a program being implemented in some health districts, a diarrheal patient aged 2 to 11 months is treated using 1 packet of ORS per day for 3 days and 1 half-tablet of $20 \mathrm{mg}$ of zinc sulfate per day for 10 days, while those aged 1 to 5 years receives 1 packet of ORS per day for 3 days and 1 tablet of $20 \mathrm{mg}$ of zinc sulfate per day for 10 days. Assuming the equal distribution of children under the age of five (children aged 2 to 11 months $=20 \%$, children aged 1 to 5 years $=80 \%$ ), the average primary drug cost per one case of diarrhea is estimated to be Int $\$ 1.48$ (ORS Int $\$ 0.40$ per packet $\times 3$ packets $)+[$ (zinc sulfate Int $\$ 0.06$ per tablet $\times 5$ tablets $) \times$ $20 \%$ of children aged 2 to 11 months) + (zinc sulfate Int $\$ 0.06$ per tablet $\times 10$ tablets) $\times 80 \%$ of children aged 1 to 5 years)] (prices of drugs refer to Table 3). From the total annual number of diarrheal episodes estimated to be $8,681,336$, we estimated that $5,121,989$ episodes $(8$, $681,336 \times 59 \%$ ) would require medical care, according to the DHS [13]. With the proportion of patients with dehydration estimated to be $43.48 \%$ of the total diarrheal patients who consult for medical care, we estimated the annual number of cases of dehydration to be 2,227,041 cases $(5,121,989 \times 43.48 \%)$. Assuming a coverage and an effectiveness of $100 \%$ for dehydration prevention, an ORS program would save an amount of Int $\$ 37,436$, 559.21 (Int $\$ 16.81 \times 2,227,041$ cases) at the national level. In terms of public health management, the cost of the dehydration prevention program should be less than this amount of savings generated by the program outcome.

To extend the significance of our model and its application to clinical management, we also compared two scenarios. We considered late treatment at the inpatient department of a hospital after 2 days of diarrheal onset, with dehydration and antibiotics use, as the worst-case scenario. We considered early treatment at the 
outpatient department of a health center within 2 days of diarrheal onset, without dehydration and antibiotics use, as the best-case scenario. Our model predicted the costs resulting from the two scenarios to be Int $\$ 354.81$ and Int $\$ 14.49$ for the worst- and the best-case, respectively. The difference (i.e. Int\$340.32) can be assumed to be savings resulting from switching from late treatment at hospital to early treatment at health center for one case. This finding shows significance in economic benefit of providing adequate and accessible primary care.

\section{Discussion}

This is a study to provide evidence on the economic burden of diarrhea in Burundi. Overall, our results indicate that diarrhea is associated with a substantial burden on both the families and the country. For instance, we found that the average cost per episode of diarrhea was Int $\$ 109.01$, which accounts for $14.5 \%$ of the GNI per capita [20]. Our study also estimated the annual economic burden of diarrhea at the national level; we found that, each year, diarrhea imposes a burden of Int $\$ 534$, 915,134, accounting for $6.4 \%$ of Burundi's GNI in 2018 [26]. However, our estimation did not take into account costs in the private sector that were previously revealed to be associated with higher cost when compared to the public sector [27-29]. Therefore, our findings could be underestimated. Contrary to some previous studies, which found that direct non-medical costs, including informal care cost, were the largest cost component [30, 31 , we found that direct medical costs were the largest component of the total cost of diarrhea. Direct medical cost accounts for $70.86 \%$ of the total cost, and the largest driver of direct medical cost was drugs and medical supplies cost $(59.2 \%)$. This could be explained by low socioeconomic conditions of our participants, resulting in low direct non-medical cost. Burundi is one of the countries with the lowest GDP per capita; thus, most of the caregivers might opt to walk to receive treatment, eat at home, and use washable cloth instead of single-use diapers. In addition, most of the caregivers were not employed and none reported their accommodation cost. On the other hand, although not explored in our study, since most of the medicines used in Burundi are imported, the price of medicines might be exorbitant.

Despite the variability of the methodology applied, our findings were somewhat similar to previous studies identified in developing countries [17, 27, 29, 31-42]. To allow for comparison of our estimated costs with results of other previous studies, we converted all results into international dollars in 2018, using the specific inflation rate and purchasing power parity rate reported for each country [21, 43]. Our estimated cost per diarrheal episode (Int\$109.01) falls within the range of findings of previous studies. Fom the societal perspective, the average cost per episode of diarrhea was estimated to be Int\$9.03, Int\$17.56, and Int\$9.62 in Gambia, Kenya, and Mali, respectively [35]. In Bangladesh, the average cost per diarrheal episode was Int\$126.95 [39]. In Vietnam, from the societal perspective, one study [29] estimated the cost per episode to be Int $\$ 213.08$ and another study [32] found the cost to be Int $\$ 528.96$ per episode. However, direct comparisons between these studies should be performed carefully since design, sites, scope of resource and service utilization, and socioeconomic characteristics of each study may vary from one study to another.

The results of the regression analysis showed that health facility type, patient type, antibiotics use, duration of the episode before consultation, MFP-insurance scheme, and complications with dehydration significantly affected the cost. Higher levels of health facility and inpatient care were associated with higher cost, which is in agreement with the literature [27, 28]. It has also been proven that the longer the duration that patients wait for a consultation at health facilities since the onset of the episode of diarrhea, the higher the cost. This result was consistent with Burkle et al. [27], who found in a study conducted in Bolivia that higher costs were also associated with a higher number of days that the patients waited for consultation. Children whose parents wait a long time to seek care after the onset of diarrhea may develop more severe diseases or complications, which may result in higher treatment costs. Therefore, interventions that could reduce the waiting time before initiating treatment are suggested as means to reduce cost; for example, improving access to health facilities or educating society to seek consultation as soon as patients develop diarrhea. The insurance scheme, "MFP", which is an insurance scheme for state officials, was found to be a factor that increases cost when compared to other health insurance schemes. This is due to the payment method of this scheme, which is fee-for-service.

Although WHO discourages the use of antibiotics for diarrhea, they were prescribed to nearly $62 \%$ of patients and were significant predictors of the cost of diarrhea. Interestingly, almost all patients who visited the health center were prescribed antibiotics. Nevertheless, this treatment pattern is consistent with previous studies conducted in Rwanda [30] and South-Africa [36] where antibiotics were used at a rate of 62 and $67 \%$, respectively.

Regarding the results of the regression analysis, savings from preventing dehydration can be applied in a costbenefit analysis of clinical practice and disease management related to providing ORS to prevent dehydration. For instance, we demonstrated that preventing one case of dehydration can save Int\$16.81. Compared to the primary treatment cost of one case in the community- 
based management program (cost of ORS and zinc sulfate is Int\$1.48/case), our estimates show that the savings per one dehydration case prevented can be used to provide primary treatment to 11 patients $(16.81 / 1.48=$ 11.36). Assuming a coverage and an effectiveness of $100 \%$ for dehydration prevention, an ORS program can save an amount of Int $\$ 37,436,559.21$ at the national level.

The community-based management program, which was recently implemented in Burundi, is an example of the ORS program recommended by WHO to manage diarrhea in developing countries [44]. The program consists of treating all cases of moderate diarrhea occurring in children aged under 5 years with oral rehydration salts and zinc by community health workers at their communities [9]. However, the the program is still limited to a few health districts. Although the evaluation of such a program was out of the scope of the present study, we demonstrated through our model that such a program could generate savings on treatment cost. Therefore, we recommend conducting a full economic evaluation of such a program as well as extension of the program to all health districts in Burundi.

In Burundi, access to health facilities seems to be adequate; the number of health centers and hospitals is estimated to be 1 health center per 10,109 inhabitants (WHO: 1 health center/10,000 inhabitants) and 1 hospital per 131,414 inhabitants (WHO: 1 hospital/150,000 inhabitants) [45]. However, access to health care is limited by the frequency of out-of-stock drugs. Stock-outs for tracer essential medicines have been observed in $45 \%$ of public health centers and $69 \%$ of public hospitals. In addition, there is unequal distribution of health professionals; most qualified health professionals are found in urban areas, while most Burundians stay in rural areas [7]. Furthermore, around $61 \%$ of Burundians are unable to pay health care fees with their usual income; they require additional sources of funding, such as working additional jobs or selling a part of their properties, or they could go into debt [46]. These factors could inhibit the promptness of treatment of diarrhea, which is a key factor to reduce cost. Therefore, in light of our regression model estimates, policymakers should improve access to health care for all Burundi inhabitants. One of the easiest ways is to improve clinical management, resulting in lower cost. Our model predicted that there would be a burden of Int $\$ 354.81$ and only Int $\$ 14.49$ per case of diarrhea in situations of late treatment at a hospital and early treatment at a health center, respectively. The difference (Int\$340.32) between these two extreme situations shows the maximum amount that can be saved with perfect management compared to a donothing strategy. This illustration should be used to raise awareness of the potential loss when nothing is done as well as the potential benefit when a comprehensive intervention is implemented. In addition, this difference can be used as a key performance indicator target in the strategic management of a comprehensive health care intervention, which aims for early prevention of dehydration (ORS program), education of clinicians to use antibiotics appropriately, education of the public to seek consultation earlier, improvement of service utilization, etc. In return, the cost savings could be used in the management of the program, which would benefit the society.

While this study has several strengths, such as consistent methods and a vast range of data collected, it also has several limitations. Firstly, our study did not estimate the cost of diarrhea by etiology because this kind of data was not available at the study health facilities. Secondly, for the unit cost of routine services for outpatient visit and bed-day, we used estimates from WHO-CHOICE; although specific to the country, these estimates may not be specific to the study health facilities. Thirdly, data collected on the severity of diarrhea were limited only to the presence or absence of dehydration, even though there are many other clinical features related to severity of diarrhea. Lastly, regarding socio-economic status of the children with diarrhea that might affect the burden estimates, we just collected data on health insurance status.

\section{Conclusion}

Diarrhea was associated with a substantial economic burden in Burundi. The cost per episode was Int $\$ 109.01$, which is considerable (14.54\%) compared to the people productivity (GDP per capita). Our model suggests that an ORS program to prevent dehydration, reduction of the use of antibiotics, and earlier consultation at health facilities can save a substantial amount and reduce the economic burden of diarrhea on society. This economic evidence provides important information to support the implementation of an ORS program and an effective service system for diarrhea in Burundi.

\section{Abbreviations \\ CMCB: Centre de Médecine Communautaire de Buyenzi; CPI: Consumer Price Index; DHS: Demographic and Health Survey; EPI: Expanded Program of Immunization; GNI: Gross National Income; GDP : Gross Domestic Product; HPRC : Prince Regent Charles Hospital; MFP : Mutuelle de la Fonction Publique; PPP: Purchasing Power Parity; ORS: Oral Rehydration Salts; SD: Standard Deviation; UNICEF: United Nations Children's Fund; WHO: World Health Organization; WHO-CHOICE: WHO-CHOosing Interventions that are Cost-Effective}

\section{Acknowledgments}

The study team acknowledges all the staff of the CMC Buyenzi health center and Prince Regent Charles Hospital and Thailand International Cooperation Agency (TICA) for their support to this study. 


\section{Authors' contributions}

Study design and conceptual framework was done by FN, AR and SY; Data collection by FN and AR; data analysis, manuscript drafting, results and discussion by FN, AR, SYand MT. All authors revised and approved the final manuscript before submission.

\section{Funding}

This work is a part of study in Master of Science program in Social, Economic and Administrative Pharmacy (SEAP), Faculty of Pharmacy, Mahidol University, Bangkok, Thailand. The study received a research grant from the SEAP program and was also supported by the Thailand International Cooperation Agency (TICA).

\section{Availability of data and materials}

All data generated or analysed during this study are included in this published article.

\section{Declarations}

\section{Ethical approval and consent to participate}

As this study was a part of a graduate study program, the study was approved by the Institutional Review Board of the Faculty of Dentistry/ Faculty of Pharmacy, Mahidol University (COA.No.MU-DT/PY-IRB 2019/ 070.1010). It was also approved by the study sites. All partcipants were given an informed consent form to sign once they agreed to participate in our study.

\section{Consent for publication}

Not applicable.

\section{Competing interests}

The authors declare that they have no competing interests.

\section{Author details}

'Master of Science Program in Social, Economic, and Administrative Pharmacy, Faculty of Pharmacy, Mahidol University, Bangkok, Thailand. 2Division of Social and Administrative Pharmacy, Department of Pharmacy, Faculty of Pharmacy, Mahidol University, 447 Sri-Ayuthaya Road, Rajathevi, Bangkok, Thailand.

\section{Received: 25 December 2020 Accepted: 9 March 2021}

\section{Published online: 12 April 2021}

\section{References}

1. Tate JE, Burton AH, Boschi-Pinto C, Parashar UD. Global, regional, and national estimates of rotavirus mortality in children $<5$ years of age, 2000 2013. Clin Infect Dis. 2016;62(Suppl 2):S96-S105. https://doi.org/10.1093/cid/ civ1013.

2. Global Burden of Disease Collaborators. Estimates of the global, regional, and national morbidity, mortality, and aetiologies of diarrhoea in 195 countries: a systematic analysis for the global burden of disease Study 2016. Lancet Infect Dis. 2018;18(11):1211-28.

3. UNICEF. Diarrhoeal disease 2019 [cited 16 Apr 2020]. Available from: https://data.unicef.org/topic/child-health/diarrhoeal-disease/.

4. Mokomane M, Kasvosve I, de Melo E, Pernica JM, Goldfarb DM. The global problem of childhood diarrhoeal diseases: emerging strategies in prevention and management. Ther Adv Infect Dis. 2018;5(1):29-43. https://doi.org/10.1177/2049936117744429.

5. Moise IK. Causes of morbidity and mortality among neonates and children in post-conflict Burundi: a cross-sectional retrospective study. Children. 2018; 5(9):125

6. World Health Organization. Diarrhoeal disease 2017 [cited 2019 July 29]. Available from: https://www.who.int/news-room/fact-sheets/detail/diarrhoea I-disease.

7. World Health Organization. Health financing for universal coverage. 2015 [cited 3 Apr 2020]. Available from: https://www.who.int/health_financing/ documents/Efficiency health_systems_Burundi/en/.

8. GAVI. Rotavirus disease and vaccines in Burundi 2013 [cited 29 Mar 2020]. Available from: https://path.azureedge.net/media/documents/VAD rota virus_burundi_fs.pdf.
9. United States Agency for International Development. Scaling up integrated community case management in Burundi 2014 [cited 20 Mar 2020]. Available from: http://siapsprogram.org/2014/05/15/scaling-up-integratedcommunity-case-management-in-burundi/.

10. Pinfold JV, Horan NJ, Mara DD. Seasonal effects on the reported incidence of acute diarrhoeal disease in Northeast Thailand. Int J Epidemiol. 1991; 20(3):777-86. https://doi.org/10.1093/ije/20.3.777.

11. Chaurasia $H$, Srivastava $S$, Kumar Singh J. Does seasonal variation affect diarrhoea prevalence among children in India? An analysis based on spatial regression models. Child Youth Serv Rev. 2020;118(C):105453.

12. Aik J, Ong J, Ng LC. The effects of climate variability and seasonal influence on diarrhoeal disease in the tropical city-state of Singapore - a time-series analysis. Int J Hyg Environ Health. 2020;227:113517. https://doi.org/10.1016/j. ijheh.2020.113517.

13. The DHS Program. Burundi DHS, 2016-2017-final report (French) 2017 [cited 29 Mar 2020]. Available from: https://dhsprogram.com/publications/publica tion-fr335-dhs-final-reports.cfm.

14. Kozma CM, Reeder CE, Schulz RM. Economic, clinical, and humanistic outcomes: a planning model for pharmacoeconomic research. Clin Ther. 1993;15(6):1121-32.

15. World Health Organization. Making choices in health: WHO guide to costeffectiveness analysis 2003 [cited 2020 March 29]. Available from: https:// www.who.int/choice/book/en/.

16. World Health Organization. Adequacy of sample size in health studies. 1990 [cited 29 Aug 2019]. Available from: https://apps.who.int/iris/handle/1 0665/41607.

17. Alkoshi S, Leshem E, Parashar UD, Dahlui M. Anticipating rotavirus vaccinesa pre-vaccine assessment of incidence and economic burden of rotavirus hospitalizations among children $<5$ year of age in Libya, 2012-13. BMC Public Health. 2015:15(1):26. https://doi.org/10.1186/s12889-015-1400-7.

18. World Health Organization. CHOosing interventions that are cost effective (WHO-CHOICE) - country-specific unit costs 2011 [cited 2020 March 26] Available from: https://www.who.int/choice/country/country_specific/en/.

19. Jamison P. Scott DG. Friction cost estimates of productivity costs in cost-ofillness studies in comparison with human capital estimates: a review. Appl Health Econ Health Policy. 2018;16(6):765-78.

20. The World Bank. GNI per capita (current LCU) - Burundi 2019 [cited 2 Apr 2020]. Available from: https://data.worldbank.org/indicator/NY.GNP.PCAP. CN?locations=BI.

21. The World Bank. PPP conversion factor, GDP (LCU per international \$) 2019 [cited 2 Apr 2020]. Available from: https://data.worldbank.org/indicator/PA NUS.PPP?locations=BI.

22. The Global Economy. Burundi: Consumer price index (CPI) 2019 [cited 2020 March 28]. Available from: https://www.theglobaleconomy.com/Burundi/cpi/.

23. World Health Organization. Guidelines for estimating the economic burden of diarrhoeal disease, with focus on assessing the costs of rotavirus diarrhoea 2005 [cited 2020 March 29]. Available from: https:/apps.who.int/ iris/handle/10665/69137

24. Belsley DA, Huh E. Regression diagnostics: Wiley; 1980. https://doi.org/10.1 002/0471725153.

25. UNICEF. Burundi/Statistics 2013 [cited 2020 April 16]. Available from: https://www.unicef.org/infobycountry/burundi_statistics.html.

26. The World Bank. GNI, PPP (current international \$) - Burundi 2018. Available from: https://data.worldbank.org/indicator/NY.GNP.MKTP.PP.CD?locations=BI.

27. Burke RM, Rebolledo PA, Embrey SR, et al. The burden of pediatric diarrhea: a cross-sectional study of incurred costs and perceptions of cost among Bolivian families. BMC Public Health. 2013;13(1):708. https://doi.org/10.11 86/1471-2458-13-708

28. Mendelsohn AS, Asirvatham JR, Mkaya Mwamburi D, et al. Estimates of the economic burden of rotavirus-associated and all-cause diarrhoea in Vellore, India. Tropical Med Int Health. 2008;13(7):934-42. https://doi.org/10.1111/j.13 65-3156.2008.02094x.

29. Fischer TK, Anh DD, Antil L, et al. Health care costs of diarrheal disease and estimates of the cost-effectiveness of rotavirus vaccination in Vietnam. J Infect Dis. 2005;192(10):1720-6. https://doi.org/10.1086/497339.

30. Ngabo F, Mvundura M, Gazley $L$, et al. The economic burden attributable to a child's inpatient admission for diarrheal disease in Rwanda. PLoS One. 2016:11(2):e0149805. https://doi.org/10.1371/journal.pone.0149805.

31. Jin H, Wang B, Fang Z, et al. Hospital-based study of the economic burden associated with rotavirus diarrhea in eastern China. Vaccine. 2011:29(44): 7801-6. https://doi.org/10.1016/j.vaccine.2011.07.104. 
32. Riewpaiboon A, Shin S, Le TP, et al. Cost of rotavirus diarrhea for programmatic evaluation of vaccination in Vietnam. BMC Public Health. 2016;16(1):777. https://doi.org/10.1186/s12889-016-3458-2.

33. Rochanathimoke O, Riewpaiboon $\mathrm{A}$, Tharmaphornpilas $\mathrm{P}$, et al. Economic burden of rotavirus diarrhea in Thailand: report from a pilot study on rotavirus vaccination. Vaccine. 2019;37(4):587-94. https://doi.org/10.1016/j.va ccine.2018.12.013.

34. Osano BO, Wang'ombe JK, Kamenwa RW, Wamalwa D. Cost analysis of care for children admitted to Kenyatta national hospital with rotavirus gastroenteritis. Vaccine. 2011;29(23):4019-24. https://doi.org/10.1016/j.va ccine.2011.03.053.

35. Rheingans R, Kukla M, Adegbola RA, et al. Exploring household economic impacts of childhood diarrheal illnesses in 3 African settings. Clin Infect Dis. 2012;55(Suppl 4):S317-26.

36. Maclntyre UE, de Villiers FP. The economic burden of diarrheal disease in a tertiary level hospital, Gauteng, South Africa. J Infect Dis. 2010;202(Suppl): S116-25. https://doi.org/10.1086/653560.

37. Pecenka C, Debellut F, Bar-Zeev N, et al. Re-evaluating the cost and costeffectiveness of rotavirus vaccination in Bangladesh, Ghana, and Malawi: a comparison of three rotavirus vaccines. Vaccine. 2018;36(49):7472-8. https:// doi.org/10.1016/j.vaccine.2018.10.068.

38. Lee WS, Poo MI, Nagaraj S. Estimates of economic burden of providing inpatient care in childhood rotavirus gastroenteritis from Malaysia. J Paediatr Child Health. 2007;43(12):818-25. https://doi.org/10.1111/j.1440-1754.2007. 01160.x.

39. Sarker AR, Sultana M, Mahumud RA, et al. Economic costs of hospitalized diarrheal disease in Bangladesh: a societal perspective. Glob Health Res Policy. 2018;3(1):1. https://doi.org/10.1186/s41256-017-0056-5.

40. Flem ET, Latipov R, Nurmatov ZS, et al. Costs of diarrheal disease and the cost-effectiveness of a rotavirus vaccination program in Kyrgyzstan. J Infect Dis. 2009;200(Suppl 1):S195-202. https://doi.org/10.1086/605040.

41. Tate JE, Rheingans RD, O'Reilly CE, et al. Rotavirus disease burden and impact and cost-effectiveness of a rotavirus vaccination program in Kenya. J Infect Dis. 2009;200(Suppl 1):S76-84. https://doi.org/10.1086/605058.

42. Bar-Zeev N, Tate JE, Pecenka C, et al. Cost-effectiveness of monovalent rotavirus vaccination of infants in Malawi: a postintroduction analysis using individual patient-level costing data. Clin Infect Dis. 2016;62(Suppl 2):S220-8. https://doi.org/10.1093/cid/civ1025.

43. World Data Atlas. World Development Indicators (WDI) 2018 [cited 202007. 08]. Available from: https://knoema.com/WBWDI2019Jan/worlddevelopment-indicators-wdi.

44. World Health Organization. The management and prevention of diarrhoea: practical guidelines 1993 [cited 2020 March 19]. Available from: https://apps, who.int/iris/bitstream/handle/10665/37036/9241544546_eng.pdf.

45. Republique du Burundi. Politique national de santé 2016-2025 2016 [cited 2020 July 12]. Available from: https://extranet.who.int/countrypla nningcycles/sites/default/files/planning_cycle_repository/burundi/pns_201 6_2025_burundi.pdf.

46. Lambert-Evans S, Ponsar F, Reid T, et al. Financial access to health care in Karuzi, Burundi: a household-survey based performance evaluation. Int J Equity Health. 2009;8:36.

\section{Ready to submit your research? Choose BMC and benefit from:}

- fast, convenient online submission

- thorough peer review by experienced researchers in your field

- rapid publication on acceptance

- support for research data, including large and complex data types

- gold Open Access which fosters wider collaboration and increased citations

- maximum visibility for your research: over $100 \mathrm{M}$ website views per year

At BMC, research is always in progress.

Learn more biomedcentral.com/submissions 